\title{
Evaluation of Acute and Chronic Toxicities of the Water Extract from Ziziphus attopensis Pierre
}

\author{
Seewaboon Sireeratawong, ${ }^{1}$ Supaporn Vannasiri, ${ }^{2}$ Urarat Nanna, ${ }^{1}$ \\ Tipaya Singhalak, ${ }^{3}$ and Kanjana Jaijoy ${ }^{4}$ \\ ${ }^{1}$ Division of Pharmacology, Department of Preclinical Science, Faculty of Medicine, Thammasat University, \\ Pathumthani 12120, Thailand \\ ${ }^{2}$ Division of Physiology, Department of Preclinical Science, Faculty of Medicine, Thammasat University, Pathumthani 12120, Thailand \\ ${ }^{3}$ Department of Animal Science, Faculty of Agricultural Technology, Chiang Mai Rajabhat University, Chiang Mai 50300, Thailand \\ ${ }^{4}$ Department of Pharmacology, Faculty of Medicine, Chiang Mai University, Chiang Mai 50200, Thailand
}

Correspondence should be addressed to Seewaboon Sireeratawong, seewaboon@gmail.com

Received 26 November 2011; Accepted 19 December 2011

Academic Editors: H. Cerecetto and A. Pittaluga

Copyright (C) 2012 Seewaboon Sireeratawong et al. This is an open access article distributed under the Creative Commons Attribution License, which permits unrestricted use, distribution, and reproduction in any medium, provided the original work is properly cited.

\begin{abstract}
We studied an acute and chronic oral toxicity of the extract from Ziziphus attopensis (ZA) in male and female SD rats according to the OECD guidelines. After a single oral administration of ZA $5 \mathrm{~g} / \mathrm{kg}$ body weight, measurement of the body and organs, necropsy, and health monitoring were performed. The body and organ weights and behavior were not changed relative to the control rats indicating that ZA does not produce acute toxicity. The chronic toxicity was determined by oral feeding both male and female rats daily with ZA at the doses of 1, 2, 4, and $8 \mathrm{~g} / \mathrm{kg}$ body weight for 180 days. Body weight changes, hematological and biochemical parameters, organ weights, gross finding, and histopathology examination were monitored during the experimental period. The results did not show any differences from the control groups. Analyses of these results with the information of signs, behavior, and health monitoring can lead to a conclusion that the long-term oral administration of ZA for 180 days does not cause chronic toxicity.
\end{abstract}

\section{Introduction}

Ziziphus is a genus of about 40 species of spiny shrubs and small trees in the Rhamnaceae family, distributed in the warm-temperate and subtropical regions throughout the world. Several pharmacological activities of plants in Ziziphus genus have been shown in many scientific literatures, such as anti-ulcerogenic of $Z$. lotus extract [1], antiproliferation of melanoma cells by $Z$. jujube [2], and antiplasmodial and antimycobacterial activities of $Z$. mauritiana [3]. Z. attopensis is one of the plants in this genus and most commonly found in sparse forests, thickets, up to $1,500 \mathrm{~m}$ in Laos and Thailand. According to Thai traditional folk medicine, the decoction of bark and wood plant of $Z$. attopensis has been commonly used as tonic, carminative, appetizer, and muscle analgesic. However, the toxicity of ZA has not been studied. The aim of the present study is therefore to evaluate the acute and chronic toxic effects of the water extract from the bark of $Z$. attopensis in SD rats.

\section{Materials and Methods}

2.1. Plant Material and Extraction. The barks of Z. attopensis were collected from Nong Khai, Thailand. The botanical identification was done at the Royal Forest Department, Bangkok, Thailand. The voucher specimen is conserved under the reference number BKF 140768. The plant material was cut into small pieces, dried in hot air oven at $50^{\circ} \mathrm{C}$ for 6 hour, and ground into a fine powder. A water decoction of herb is one of the effective methods used in ayurvedic and Thai traditional medicine. A decoction of $Z$. attopensis dried bark was prepared as follows: one kilogram of bark powder of $Z$. attopensis was suspended 


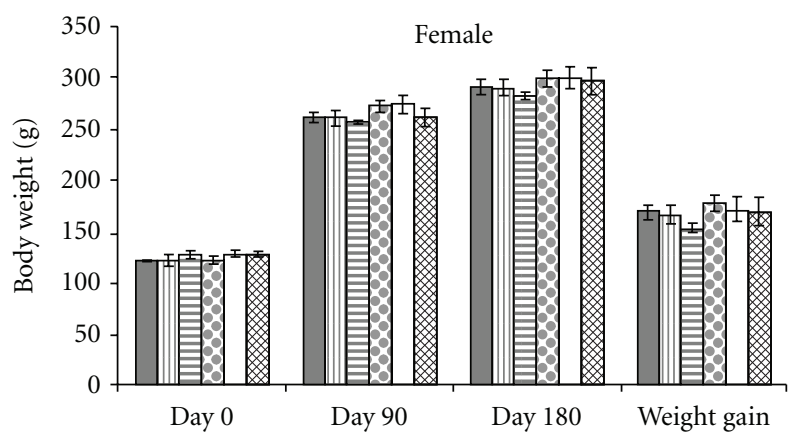

(a)
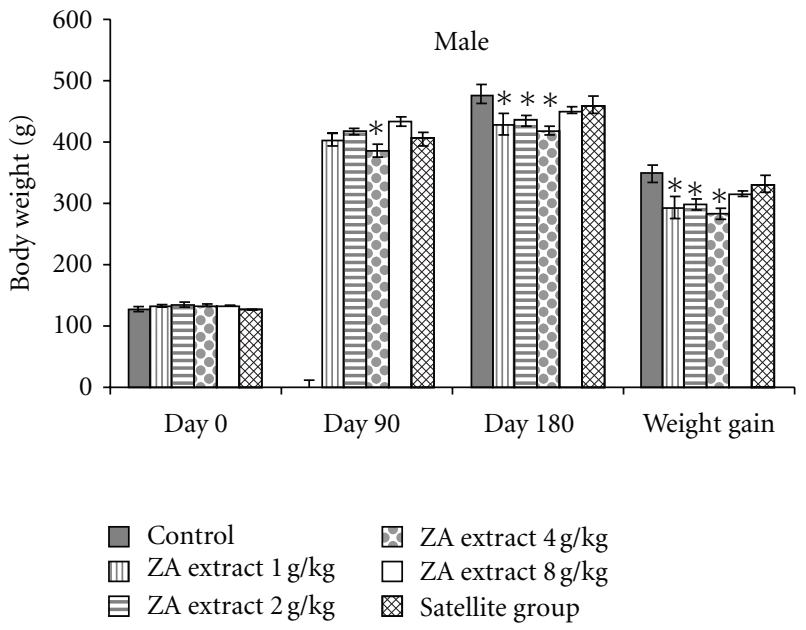

(b)

FIGURE 1: Body weights of rats in chronic toxicity of ZA extract.

TABLE 1: Hematological values of female rats in chronic toxicity of ZA extract.

\begin{tabular}{llccccc}
\hline & Control & \multicolumn{3}{c}{ ZA extract } \\
& & $1 \mathrm{~g} / \mathrm{kg}$ & $2 \mathrm{~g} / \mathrm{kg}$ & $4 \mathrm{~g} / \mathrm{kg}$ & $8 \mathrm{~g} / \mathrm{kg}^{\mathrm{a}}$ & $8 \mathrm{~g} / \mathrm{kg}^{\mathrm{b}}$ \\
\hline RBC $\left(\times 10^{6} / \mu \mathrm{l}\right)$ & $7.57 \pm 0.11$ & $7.61 \pm 0.17$ & $7.13 \pm 0.24$ & $7.26 \pm 0.09$ & $7.05 \pm 0.30$ & $7.32 \pm 0.11$ \\
HGB $(\mathrm{g} / \mathrm{dL})$ & $15.20 \pm 0.18$ & $14.94 \pm 0.84$ & $14.36 \pm 0.43$ & $14.48 \pm 0.20$ & $14.78 \pm 0.14$ & $15.07 \pm 0.21$ \\
HCT $(\%)$ & $46.10 \pm 0.58$ & $46.90 \pm 1.04$ & $43.40 \pm 1.54$ & $44.20 \pm 0.61$ & $42.80 \pm 1.81^{*}$ & $46.00 \pm 0.60$ \\
MCV $(\mathrm{fl})$ & $60.60 \pm 0.30$ & $61.76 \pm 0.49^{*}$ & $60.77 \pm 0.33$ & $61.04 \pm 0.34$ & $60.85 \pm 0.35$ & $62.69 \pm 0.20^{*}$ \\
MCH $(\mathrm{pg})$ & $20.08 \pm 0.18$ & $19.58 \pm 0.96$ & $20.13 \pm 0.12$ & $19.96 \pm 0.11$ & $21.48 \pm 1.36$ & $20.60 \pm 0.06$ \\
MCHC $(\mathrm{g} / \mathrm{dL})$ & $33.14 \pm 0.25$ & $31.67 \pm 1.44$ & $33.13 \pm 0.32$ & $32.69 \pm 0.26$ & $35.30 \pm 2.25$ & $32.83 \pm 0.12$ \\
Platelet $\left(\times 10^{5} / \mu \mathrm{l}\right)$ & $6.28 \pm 0.38$ & $6.14 \pm 0.64$ & $6.90 \pm 0.66$ & $6.96 \pm 0.52$ & $5.96 \pm 0.62$ & $6.94 \pm 0.46$ \\
\hline
\end{tabular}

Values are expressed as mean \pm SEM, $n=10$.

* Significantly different from control, $P<0.05$.

${ }^{\mathrm{a}} \mathrm{A}$ group was given ZA extract at $8 \mathrm{~g} / \mathrm{kg}$ daily over 180 days.

${ }^{\mathrm{b}} \mathrm{A}$ satellite group was given ZA extract at $8 \mathrm{~g} / \mathrm{kg}$ daily over 180 days followed by no treatment for 28 days.

in fourteen liters of distilled water, brought to a strong boil, and then simmered at low heat for 3-4 hours. The residue from the filtration was boiled and filtered again. The filtrates were collected and evaporated in a rotary evaporator until concentrated. The ZA extract was stored at $4-5^{\circ} \mathrm{C}$ after preparation.

2.2. Experimental Animals. Male and female SpragueDawley (SD) rats, weighing 120-140 g, were detained from the National Laboratory Animal Center (NLAC), Nakhon Pathom. They were housed under standard environmental conditions of temperature at $25 \pm 1^{\circ} \mathrm{C}$ under a $12 \mathrm{~h}$ dark-light cycle and allowed free access to drinking water and standard pellet diet. All experimental protocols were approved by the Animal Ethics Committee of the Faculty of Medicine, Thammasat University (no. 0001/2005).

2.3. Acute Oral Toxicity Study. According to the Organization of Economic Co-operation and Development (OECD) guideline for testing of chemicals [4] and the World Health
Organization (WHO) guideline [5], acute oral toxicity was examined in male and female SD rats. Twenty rats of each sex were randomly divided into two groups of ten animals. Rats were deprived of food except water 16-18 hour prior to the experiments. Test substance at the dose of $5,000 \mathrm{mg} / \mathrm{kg}$ body weight was orally given once to one group of animals whereas the control group administered with vehicle. Neither food nor water was given up to $4 \mathrm{~h}$ after the treatment. Body weight, body weight change, signs of toxicity, behaviors and mortality were observed for the initial 24th hour after administration and once daily for 14 days. At the end of the experiment period, all rats were sacrificed with overdose of pentobarbital sodium $(100 \mathrm{mg} / \mathrm{kg}$, intraperitoneal injection) for necropsy examination. The internal organs such as heart, lungs, livers, kidneys, spleen, adrenals, sex organs, and brain were performed on gross pathology and histopathological examination.

2.4. Chronic Toxicity Study. The animals were divided into six groups of twenty animals (ten male and ten female). Test 
TABLE 2: Hematological values of male rats in chronic toxicity of ZA extract.

\begin{tabular}{llccccc}
\hline & Control & \multicolumn{3}{c}{ ZA extract } & & \\
& & $1 \mathrm{~g} / \mathrm{kg}$ & $2 \mathrm{~g} / \mathrm{kg}$ & $4 \mathrm{~g} / \mathrm{kg}$ & $8 \mathrm{~g} / \mathrm{kg}^{\mathrm{a}}$ & $7.84 \pm 0.37^{*}$ \\
\hline RBC $\left(\times 10^{6} / \mu \mathrm{l}\right)$ & $8.15 \pm 0.09$ & $8.13 \pm 0.17$ & $7.86 \pm 0.25$ & $7.81 \pm 0.10$ & $7.44 \pm 0.09$ \\
HGB $(\mathrm{g} / \mathrm{dL})$ & $15.64 \pm 0.14$ & $15.38 \pm 0.29$ & $14.99 \pm 0.44$ & $15.11 \pm 0.12$ & $15.22 \pm 0.03$ & $15.37 \pm 0.13$ \\
HCT $(\%)$ & $47.60 \pm 0.52$ & $47.00 \pm 0.92$ & $45.90 \pm 1.51$ & $46.10 \pm 0.50$ & $44.10 \pm 2.10^{*}$ & $46.80 \pm 0.25$ \\
MCV $(\mathrm{fl})$ & $58.42 \pm 0.34$ & $57.87 \pm 0.33$ & $58.42 \pm 0.34$ & $59.12 \pm 0.37$ & $59.21 \pm 0.27$ & $56.60 \pm 3.26$ \\
MCH $(\mathrm{pg})$ & $19.19 \pm 0.13$ & $18.92 \pm 0.13$ & $19.11 \pm 0.12$ & $19.38 \pm 0.19$ & $21.04 \pm 1.48^{*}$ & $19.57 \pm 0.15$ \\
MCHC $(\mathrm{g} / \mathrm{dL})$ & $32.84 \pm 0.08$ & $32.68 \pm 0.14$ & $32.70 \pm 0.18$ & $32.75 \pm 0.28$ & $35.52 \pm 2.46$ & $32.52 \pm 0.33$ \\
Platelet $\left(\times 10^{5} / \mu \mathrm{l}\right)$ & $6.48 \pm 0.72$ & $7.54 \pm 0.55$ & $6.99 \pm 0.84$ & $8.31 \pm 0.36^{*}$ & $7.24 \pm 0.48$ & $7.86 \pm 0.30$ \\
\hline
\end{tabular}

Values are expressed as mean \pm SEM, $n=10$.

* Significantly different from control, $P<0.05$.

a group was given ZA extract at $8 \mathrm{~g} / \mathrm{kg}$ daily over 180 days.

${ }^{\mathrm{b}} \mathrm{A}$ satellite group was given ZA extract at $8 \mathrm{~g} / \mathrm{kg}$ daily over 180 days followed by no treatment for 28 days.

TABLE 3: Clinical blood chemistry values of female rats in chronic toxicity of ZA extract.

\begin{tabular}{|c|c|c|c|c|c|c|}
\hline & \multirow{2}{*}{ Control } & \multicolumn{5}{|c|}{ ZA extract } \\
\hline & & $1 \mathrm{~g} / \mathrm{kg}$ & $2 \mathrm{~g} / \mathrm{kg}$ & $4 \mathrm{~g} / \mathrm{kg}$ & $8 \mathrm{~g} / \mathrm{kg}^{\mathrm{a}}$ & $8 \mathrm{~g} / \mathrm{kg}^{\mathrm{b}}$ \\
\hline Glucose (mg/dL) & $104.90 \pm 4.94$ & $100.40 \pm 3.77$ & $97.70 \pm 2.94$ & $98.00 \pm 4.28$ & $99.90 \pm 6.25$ & $103.50 \pm 6.26$ \\
\hline BUN (mg/dL) & $18.90 \pm 0.90$ & $18.80 \pm 0.99$ & $19.30 \pm 0.63$ & $17.10 \pm 0.96$ & $17.00 \pm 0.61$ & $19.50 \pm 0.70$ \\
\hline Creatinine (mg/dL) & $0.34 \pm 0.02$ & $0.35 \pm 0.02$ & $0.31 \pm 0.01$ & $0.31 \pm 0.01$ & $0.33 \pm 0.01$ & $0.39 \pm 0.02$ \\
\hline Total protein $(\mathrm{g} / \mathrm{dL})$ & $5.15 \pm 0.09$ & $5.23 \pm 0.17$ & $5.19 \pm 0.09$ & $5.18 \pm 0.05$ & $5.21 \pm 0.10$ & $5.60 \pm 0.10^{*}$ \\
\hline Albumin $(\mathrm{g} / \mathrm{dL})$ & $2.80 \pm 0.07$ & $2.74 \pm 0.09$ & $2.67 \pm 0.05$ & $2.72 \pm 0.05$ & $2.72 \pm 0.06$ & $2.98 \pm 0.08$ \\
\hline Total bilirubin (mg/dL) & $0.12 \pm 0.01$ & $0.19 \pm 0.04$ & $0.19 \pm 0.06$ & $0.10 \pm 0.00$ & $0.13 \pm 0.02$ & $0.21 \pm 0.03$ \\
\hline Direct bilirubin $(\mathrm{mg} / \mathrm{dL})$ & $0.05 \pm 0.03$ & $0.12 \pm 0.06$ & $0.13 \pm 0.07$ & $0.02 \pm 0.01$ & $0.07 \pm 0.03$ & $0.17 \pm 0.04$ \\
\hline SGOT $(\mathrm{U} / \mathrm{l})$ & $145.00 \pm 13.32$ & $136.80 \pm 11.21$ & $148.50 \pm 8.52$ & $121.10 \pm 12.80$ & $160.70 \pm 21.23$ & $182.90 \pm 16.92$ \\
\hline SGPT (U/l) & $49.00 \pm 8.48$ & $35.20 \pm 1.44$ & $43.30 \pm 6.04$ & $34.20 \pm 3.52$ & $43.90 \pm 10.82$ & $47.10 \pm 5.38$ \\
\hline $\operatorname{ALP}(\mathrm{U} / \mathrm{l})$ & $33.40 \pm 1.33$ & $36.00 \pm 2.44$ & $33.60 \pm 1.98$ & $36.20 \pm 1.40$ & $35.90 \pm 2.15$ & $31.80 \pm 1.83$ \\
\hline
\end{tabular}

Values are expressed as mean $\pm \mathrm{SEM}, n=10$.

* Significantly different from control, $P<0.05$.

${ }^{\text {a }} \mathrm{A}$ group was given $\mathrm{ZA}$ extract at $8 \mathrm{~g} / \mathrm{kg}$ daily over 180 days.

${ }^{\mathrm{b}} \mathrm{A}$ satellite group was given ZA extract at $8 \mathrm{~g} / \mathrm{kg}$ daily over 180 days followed by no treatment for 28 days.

substance was administered orally at the doses of $1,2,4$, and $8 \mathrm{~g} / \mathrm{kg}$ daily for 180 days, but the control group received an equal volume of vehicle. In order to access reversibility, the water extract was given to a group of rats (satellite group) at $8 \mathrm{~g} / \mathrm{kg}$ once daily for 180 days and no treatment for the following 28 days. The toxic manifestations such as signs of toxicity, mortality, and the body weight changes were monitored daily $[5,6]$.

At the end of each experiment, rats were anesthetized with pentobarbital sodium (intraperitoneal injection, i.p.) and blood collected with heparinized and nonheparinized tubes from common carotid artery for hematological and blood chemical studies, respectively. After blood collection, the internal organs (heart, lungs, thymus, livers, kidneys, spleen, adrenals, small intestine, stomach and duodenum, muscle with sciatic nerve, thoracic spines, brain, eyes, sex organs, uterus, and epididymis) were isolated and weighted to determine relative organs weights and observed for gross lesions. All tissues were preserved in 10\% neutral buffered formaldehyde solution for histopathological examination.
2.4.1. Measurement of Hematological and Blood Chemical Parameters in Rats. The heparinized blood $(2.5 \mathrm{~mL})$ was subjected to hematological tests using the Sysmex K-1000 fully automated hematology analyzer for measuring white blood cell and differential leukocyte count, platelet, hematocrit, and hemoglobin contents. The nonheparinized blood $(5 \mathrm{~mL})$ was allowed to coagulate, then centrifuged, and the serum was separated. Serum was assayed for glucose, blood urea nitrogen (BUN), creatinine, total protein, albumin, total bilirubin, direct bilirubin, serum glutamic-oxaloacetic transaminase (SGOT), serum glutamic-pyruvic transaminase (SGPT), and alkaline phosphatase (ALP). These levels were determined automatically by using the COBAS INTEGRA System.

2.4.2. Histopathological Examination of the Internal Organs. Samples of the internal organs were dehydrated by serial ethanol solution and enclosed with paraffin. Micrometer sections $(5 \mu \mathrm{m})$ cut with microtome were stained with hematoxylin and eosin ( $\mathrm{H} \& \mathrm{E})$ and examined under a light microscope; photomicrographs of the samples were recorded. 
Control

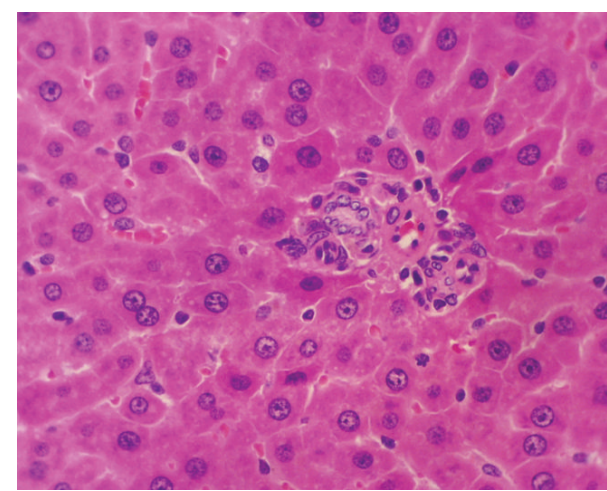

ZA extract $2 \mathrm{~g} / \mathrm{kg}$

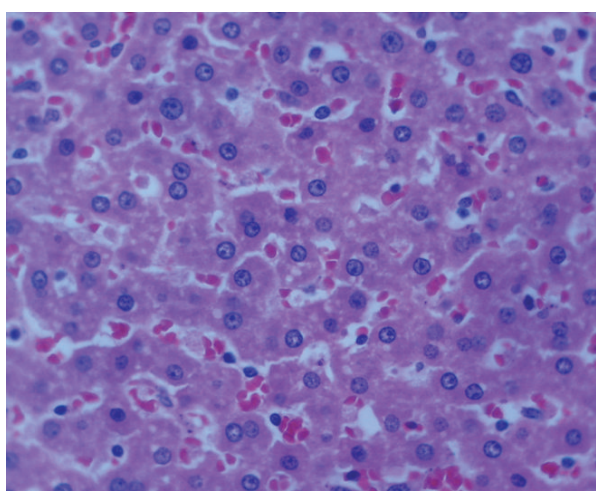

ZA extract $8 \mathrm{~g} / \mathrm{kg}$

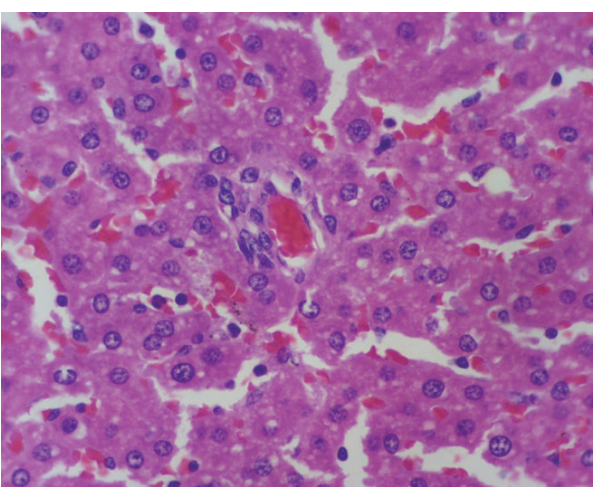

ZA extract $1 \mathrm{~g} / \mathrm{kg}$

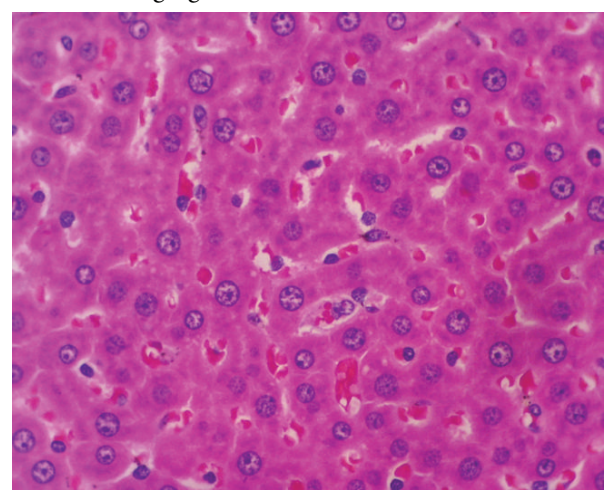

ZA extract $4 \mathrm{~g} / \mathrm{kg}$

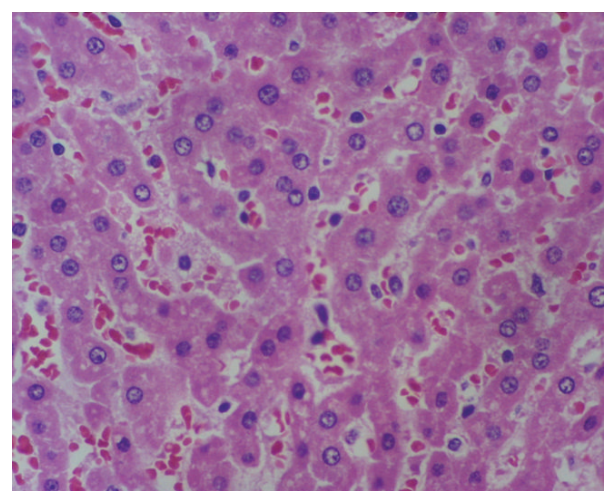

Satellite group

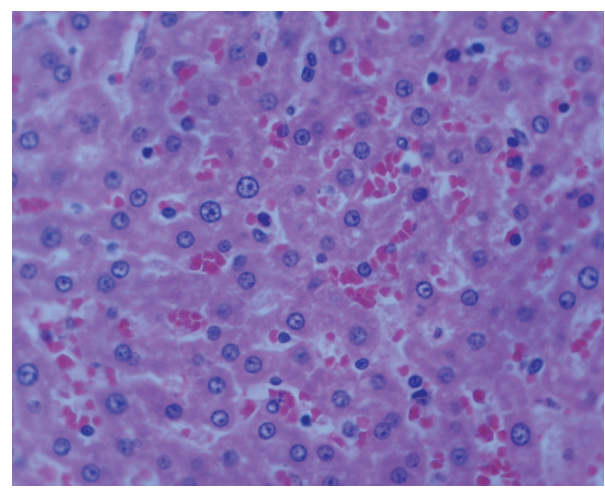

FIGURE 2: The histopathology of female liver from the control and treated groups (the 10x magnifications). No significant damage was detected in any treatment group.

2.5. Statistical Analysis. Results were expressed as mean \pm standard error of mean (SEM). Statistical significance was determined by one-way analysis of variance (ANOVA) and post hoc least-significant difference (LSD) test. The data obtained from acute toxicity study were analyzed using Student's $t$-test. $P$ values less than 0.05 were considered significant.

\section{Results and Discussion}

3.1. Acute Oral Toxicity. Single oral administration of ZA extract at a dose of $5 \mathrm{~g} / \mathrm{kg}$ did not show visible signs of toxicity, abnormal behaviors, and mortality. Neither body weight nor internal organ weight of treated rats was significantly changed relative to that of the control group (data not shown). Furthermore, gross and pathological examinations of the internal organs revealed no pathological abnormality. According to OECD guideline [4] and Kennedy et al. [7], substances that explain the median lethal dose $\left(\mathrm{LD}_{50}\right)$ higher than $5 \mathrm{~g} / \mathrm{kg}$ body weight by oral route can be considered practically nontoxic. Thus, it can be concluded that ZA extract is absent of the acute oral toxicity.

3.2. Chronic Oral Toxicity. The rats in chronic toxicity study daily received the ZA extract at the doses of $1,2,4$, and $8 \mathrm{~g} / \mathrm{kg}$ for 180 days. No clinical toxicity signs and mortality 


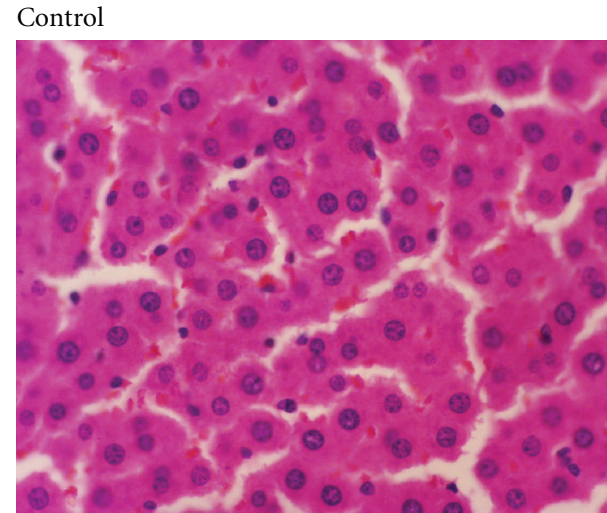

ZA extract $2 \mathrm{~g} / \mathrm{kg}$

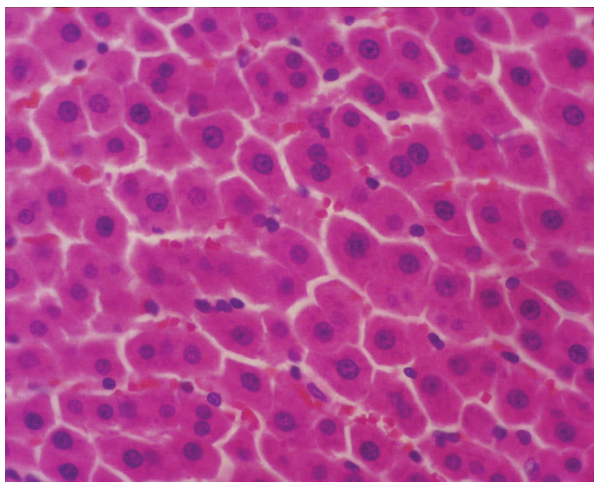

ZA extract $8 \mathrm{~g} / \mathrm{kg}$

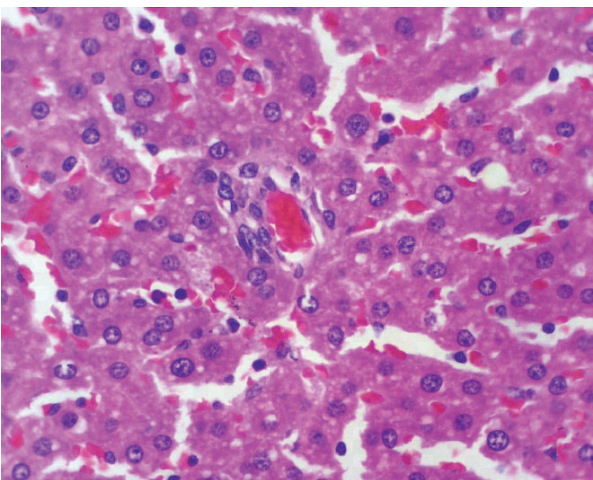

ZA extract $1 \mathrm{~g} / \mathrm{kg}$

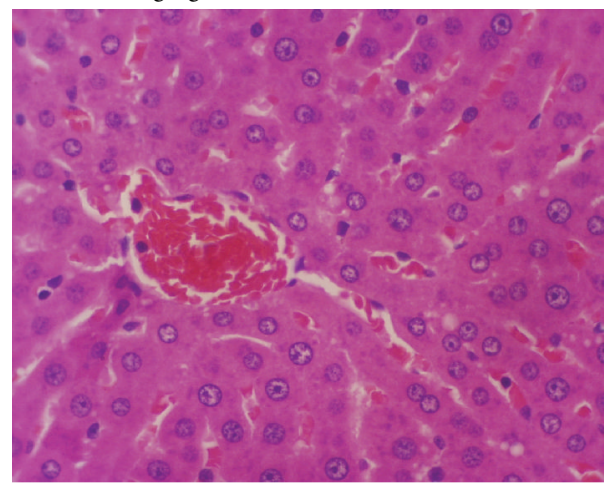

ZA extract $4 \mathrm{~g} / \mathrm{kg}$

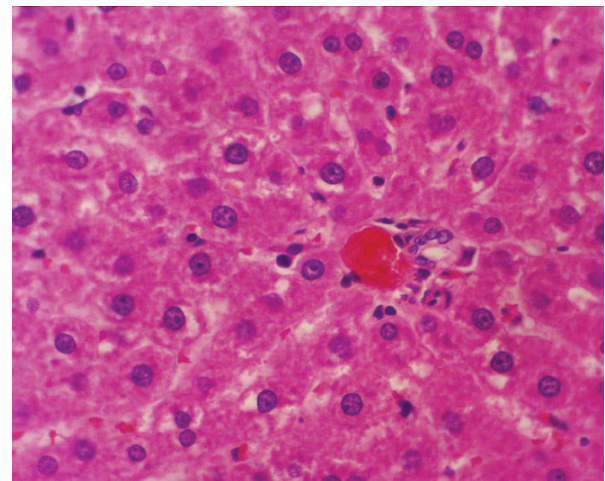

Satellite group

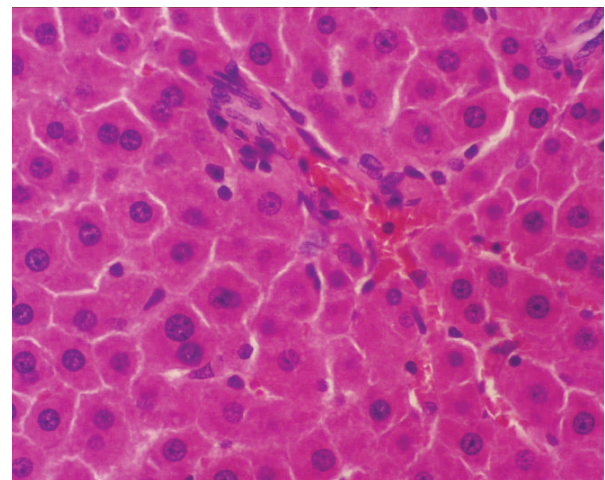

FIGURE 3: The histopathology of male liver from the control and treated groups (the 10x magnifications). No significant damage was detected in any treatment group.

were observed in the treated group compared to the control group. Figure 1 shows the effects of the ZA extract on body weight and body weight gain of female and male rats. The body weight gain of the male rats treated with ZA extract at 1,2 , and $4 \mathrm{~g} / \mathrm{kg}$ was significantly decreased as compared with that of the control group. However, food intake of all groups was not significantly altered, and there was no sign of morbidity and diseases after monitoring animal health in the entire period of 180 days. Although the weights of some internal organs of male rats (data not shown) were found to be statistically different from the control groups, they did not exhibit any gross morphological changes. Therefore, it seems to be of little toxicological significance.
The hematopoietic system is very sensitive to toxic compounds and can be altered by the ingestion of some toxic plants. The changes in the hematological system have a higher predictive value for human toxicity, when the data are translated from animal studies [8]. The status of bone marrow activity and intravascular effects were monitored by hematological examination [9]. Moreover, the morphological examination of red blood cells and white blood cells indicates their production or destruction. White blood cell counts (basophil, eosinophil, lymphocyte, monocyte, and neutrophil) are also performed in order to evaluate immune system [9-11]. In the present study, some of the hematological values of female and male treated 
TABLE 4: Clinical blood chemistry values of male rats in chronic toxicity of ZA extract.

\begin{tabular}{|c|c|c|c|c|c|c|}
\hline & \multirow{2}{*}{ Control } & \multicolumn{5}{|c|}{ ZA extract } \\
\hline & & $1 \mathrm{~g} / \mathrm{kg}$ & $2 \mathrm{~g} / \mathrm{kg}$ & $4 \mathrm{~g} / \mathrm{kg}$ & $8 \mathrm{~g} / \mathrm{kg}^{\mathrm{a}}$ & $8 \mathrm{~g} / \mathrm{kg}^{\mathrm{b}}$ \\
\hline Glucose (mg/dL) & $117.30 \pm 5.90$ & $116.70 \pm 6.05$ & $122.80 \pm 2.48$ & $122.40 \pm 7.28$ & $121.00 \pm 6.11$ & $117.50 \pm 4.61$ \\
\hline BUN (mg/dL) & $19.20 \pm 0.70$ & $19.00 \pm 1.04$ & $21.50 \pm 1.86$ & $18.70 \pm 0.65$ & $19.40 \pm 0.92$ & $17.90 \pm 0.46$ \\
\hline Creatinine (mg/dL) & $0.29 \pm 0.02$ & $0.29 \pm 0.02$ & $0.31 \pm 0.01$ & $0.31 \pm 0.02$ & $0.31 \pm 0.01$ & $0.30 \pm 0.00$ \\
\hline Total protein (g/dL) & $4.90 \pm 0.05$ & $4.83 \pm 0.09$ & $5.13 \pm 0.08$ & $5.19 \pm 0.10^{*}$ & $5.00 \pm 0.11$ & $5.33 \pm 0.09^{*}$ \\
\hline Albumin $(\mathrm{g} / \mathrm{dL})$ & $2.65 \pm 0.04$ & $2.48 \pm 0.05^{*}$ & $2.57 \pm 0.03$ & $2.67 \pm 0.04$ & $2.56 \pm 0.04$ & $2.71 \pm 0.06$ \\
\hline Total bilirubin (mg/dL) & $0.10 \pm 0.00$ & $0.11 \pm 0.01$ & $0.15 \pm 0.03^{*}$ & $0.12 \pm 0.01$ & $0.10 \pm 0.00$ & $0.13 \pm 0.01$ \\
\hline Direct bilirubin $(\mathrm{mg} / \mathrm{dL})$ & $0.00 \pm 0.00$ & $0.04 \pm 0.02$ & $0.03 \pm 0.02$ & $0.05 \pm 0.03$ & $0.01 \pm 0.01$ & $0.07 \pm 0.03^{*}$ \\
\hline SGOT (U/l) & $120.80 \pm 14.62$ & $129.60 \pm 12.93$ & $122.90 \pm 11.83$ & $138.80 \pm 16.10$ & $119.40 \pm 9.66$ & $168.10 \pm 9.84^{*}$ \\
\hline SGPT (U/l) & $46.70 \pm 4.91$ & $39.30 \pm 2.07$ & $41.70 \pm 1.58$ & $45.10 \pm 3.47$ & $42.90 \pm 2.53$ & $42.30 \pm 1.83$ \\
\hline $\operatorname{ALP}(\mathrm{U} / \mathrm{l})$ & $53.10 \pm 2.86$ & $66.20 \pm 12.60$ & $80.40 \pm 7.61^{*}$ & $75.80 \pm 9.73^{*}$ & $62.30 \pm 5.14$ & $48.00 \pm 3.31$ \\
\hline
\end{tabular}

Values are expressed as mean $\pm \mathrm{SEM}, n=10$.

* Significantly different from control, $P<0.05$.

${ }^{a} \mathrm{~A}$ group was given $\mathrm{ZA}$ extract at $8 \mathrm{~g} / \mathrm{kg}$ daily over 180 days.

${ }^{\mathrm{b}} \mathrm{A}$ satellite group was given ZA extract at $8 \mathrm{~g} / \mathrm{kg}$ daily over 180 days followed by no treatment for 28 days.

rats were slightly different from those of the control group (Tables 1 and 2); nonetheless, the differential white blood cell count values showed no difference between the control and the treated groups (data not shown). Because all values lay within the normal limits $[12,13]$. Thus, the changes in all of the criteria do not suggest that ZA extract produces chronic toxicity.

Clinical blood chemistry examination was further performed in order to intensely evaluate any toxic effects on the pancreas function (glucose), kidney function (BUN, creatinine), and liver function (SGOT, SGPT, ALP, total protein, albumin, and total and direct bilirubin) $[11,14]$. In both female and male groups, some clinical blood chemistry values such as total protein, albumin, bilirubin, SGOT, and ALP were statistically different from that of the control group (Tables 3 and 4). Nevertheless, these values are within the normal range [15-18]. Bilirubin levels increase in anemia, that is, a result of a hemolytic process [19]. The increased levels of SGOT and SGPT in the blood are associated with the damage of hepatic cells [20]. Moreover, the increase of serum protein level is an indication of the tissue injury and reflection of hepatic toxicity [21]. This observation of a major increase in the levels of liver enzymes may indicate the hepatotoxicity of ZA. The histopathological analysis of the liver showed no alteration in the liver structure of ZAtreated rats (Figures 2 and 3 ).

In conclusion, the present study demonstrated that the water extract from the bark of $Z$. attopensis did not produce any toxic signs and symptoms of acute and chronic oral toxicity tests. Moreover, it did not cause any lethality nor produced any remarkable hematological, and blood chemical adverse effects both in chronic toxicity studies in SD rats.

\section{Acknowledgments}

The authors are thankful to the Department for Development of Thai Traditional and Alternative Medicine Ministry of Public Health for financial support and the Royal Forest
Department, Bangkok, Thailand for the plant material identification.

\section{References}

[1] B. Wahida, B. Abderrahman, and C. Nabil, "Antiulcerogenic activity of Zizyphus lotus (L.) extracts," Journal of Ethnopharmacology, vol. 112, no. 2, pp. 228-231, 2007.

[2] C.-F. Hung, B.-Y. Hsu, S.-C. Chang, and B.-H. Chen, "Antiproliferation of melanoma cells by polysaccharide isolated from Zizyphus jujuba," Nutrition, vol. 28, no. 1, pp. 98-105, 2012.

[3] P. Panseeta, K. Lomchoey, S. Prabpai et al., "Antiplasmodial and antimycobacterial cyclopeptide alkaloids from the root of Ziziphus mauritiana," Phytochemistry, vol. 72, no. 9, pp. 909915, 2011.

[4] OECD, "Test guideline 425. Acute oral toxicity-Up-andDown-Procedure (UDP)," in OECD Guideline for Testing of Chemical, Section 4-Health Effects, Organization of Economic Co-operation and Development, Paris, France, 2001.

[5] WHO, General Guidelines for Methodologies on Research and Evaluation of Traditional Medicine, World Health Organization, Geneva, Switzerland, 2000.

[6] OECD, "Test guideline 452. Chronic toxicity studies," in OECD Guideline for Testing of Chemical, Section 4-Health Effects, Organization of Economic Co-operation and Development, Paris, France, 1981.

[7] G. L. Kennedy, R. L. Ferenz, and B. A. Burgess, "Estimation of acute oral toxicity in rats by determination of the approximate lethal dose rather than the $\mathrm{LD}_{50}$," Journal of Applied Toxicology, vol. 6, no. 3, pp. 145-148, 1986.

[8] A. A. Adeneye, O. P. Ajagbonna, T. I. Adeleke, and S. O. Bello, "Preliminary toxicity and phytochemical studies of the stem bark aqueous extract of Musanga cecropioides in rats," Journal of Ethnopharmacology, vol. 105, no. 3, pp. 374-379, 2006.

[9] L. V. Gregg, "Anemias and polychythenias," in Hematology Techniques and Concepts for Veterinary Technicians, pp. 95101, Iowa State University Press, Iowa, USA, 2000.

[10] J. W. Williams, D. A. Nelson, and M. W. Morris, "Examination of the blood," in Hematology International, J. W. William, Ed., pp. 9-24, McGraw-Hill, New York, NY, USA, 4th edition, 1990. 
[11] B. S. Levine, "Animal clinical pathology," in CRC Handbook of Toxicology, M. J. Derelanko and M. A. Hollinger, Eds., pp. 742-768, CRC Press, New York, NY, USA, 2nd edition, 2002.

[12] B. V. Feldman, J. G. Zinkl, and N. C. Jain, Schalm's Veterinary Hematology, Lea Febiger, Philadelphia, Pa, USA, 5th edition, 2000.

[13] P. Inala, A. Sirimontaporn, R. Inpunkaew et al., "Hematological analysis of outbred Sprague-Dawley rat in the Facility of National Laboratory Animal Centre," in Proceedings of the 28th Congress on science and technology of Thailand, Bangkok, Thailand, 2002.

[14] L.Y. Young and E. G. Holland, The Clinical Use of Drugs: Interpretation of Clinical Laboratory Tests, Lippincott Williams \& Wilkins, Vancouver, BC, Canada, 6th edition, 1995.

[15] J. D. Caisey and D. J. King, "Clinical chemical values for some common laboratory animals," Clinical Chemistry, vol. 26, no. 13, pp. 1877-1879, 1980.

[16] R. A. Sacher and R. A. McPherson, "General chemistry," in Widmann's Clinical Interpretation of Laboratory Test, pp. 318365, F.A. Davis Company, Philadelphia, Pa, USA, 10th edition, 1991.

[17] R. A. Sacher and R. A. McPherson, "Test of liver function," in Widmann's Clinical Interpretation of Laboratory Test, pp. 416443, F.A. Davis Company, Philadelphia, Pa, USA, 10th edition, 1991.

[18] W. Angkhasirisap, P. Inala, A. Sirimontaporn et al., "Blood chemistry profiles of outbred Sprague-Dawley rat in the Facility of National Laboratory Animal Centre," in Proceedings of the 28th Congress on Science and Technology of Thailand, Bangkok, Thailand, 2002.

[19] E. O. Orish, O. J. Johnson, M. A. Chude, E. Obi, and C. E. Dioka, "Sub-chronic toxicity studies of the aqueous extract of Boerhavia diffusa leaves," Journal of Health Science, vol. 49, no. 6, pp. 444-447, 2003.

[20] P. Witthawaskul, A. Panthong, D. Kanjanapothi, T. Taesothikul, and N. Lertprasertsuke, "Acute and subacute toxicities of the saponin mixture isolated from Schefflera leucantha Viguier," Journal of Ethnopharmacology, vol. 89, no. 1, pp. 115121, 2003.

[21] F. E. Solomon, A. C. Sharada, and P. U. Devi, “Toxic effects of crude root extract of Plumbago rosea (Rakta chitraka) on mice and rats," Journal of Ethnopharmacology, vol. 38, no. 1, pp. 7984, 1993. 

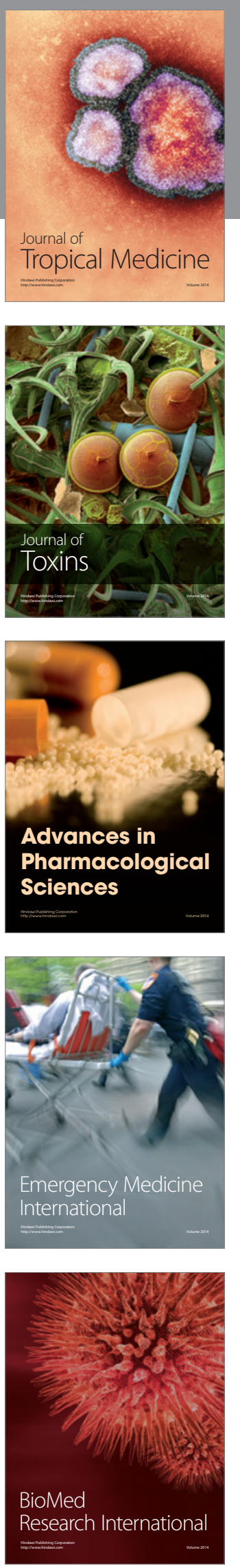
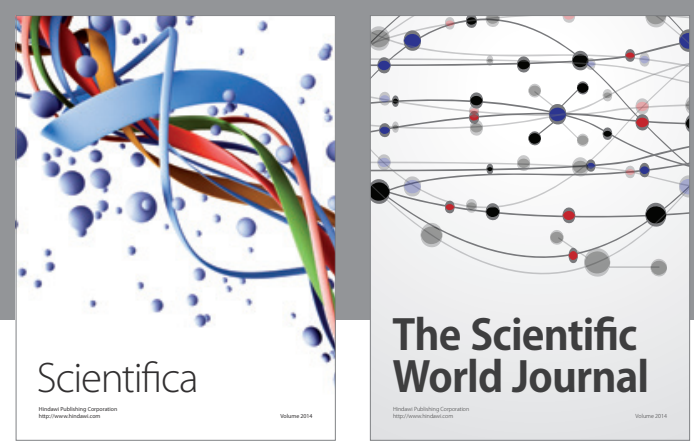

The Scientific World Journal
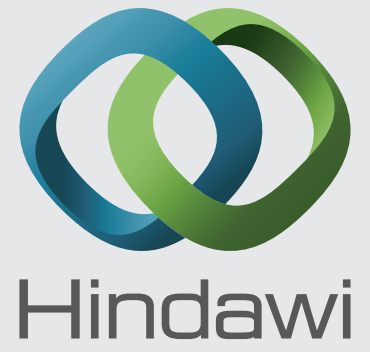

Submit your manuscripts at

http://www.hindawi.com
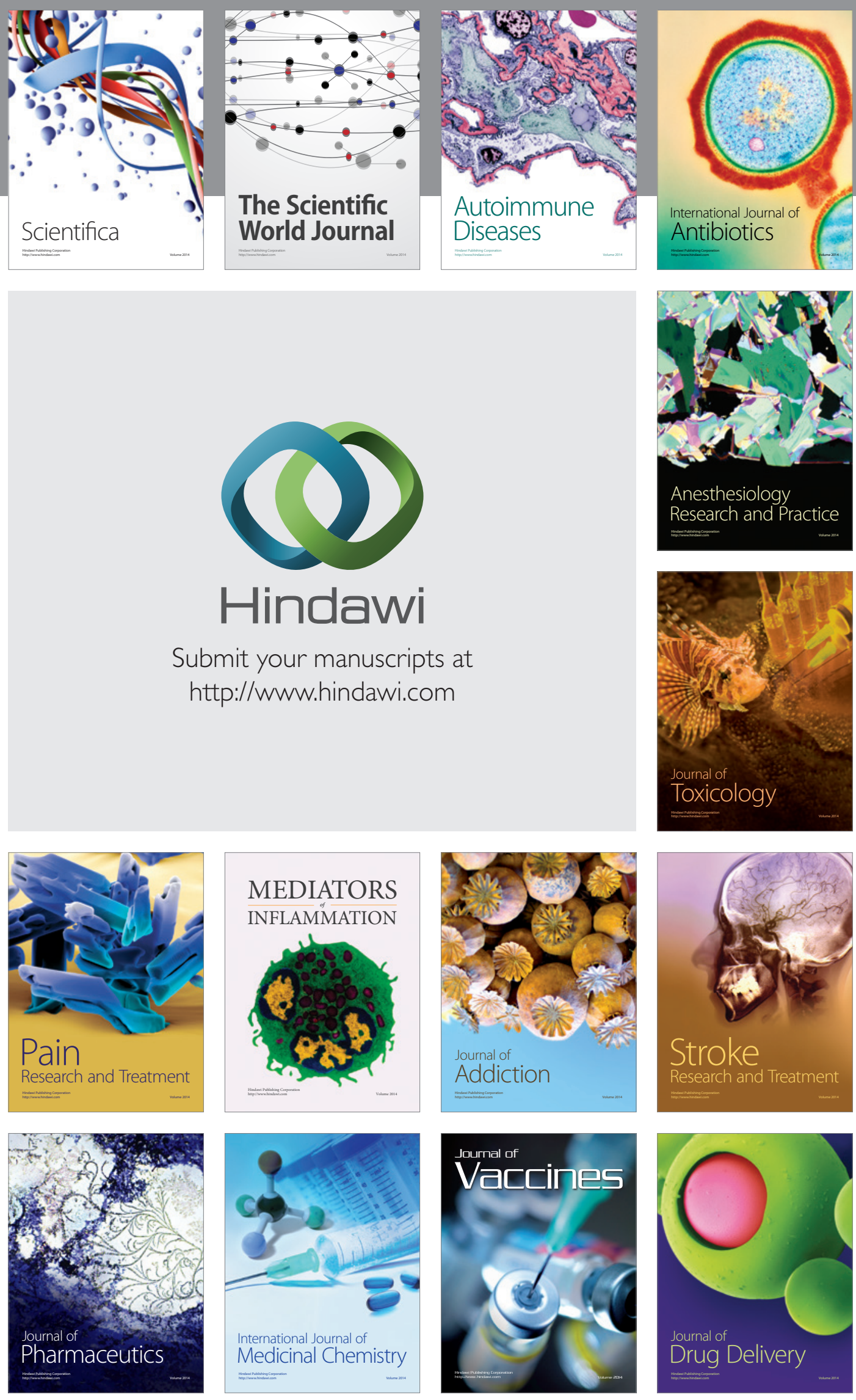